\title{
Probabilistic Projections of the Atlantic Overturning
}

\author{
Carl-Friedrich Schleussner • Anders \\ Levermann - Malte Meinshausen
}

Received: date / Accepted: date

\begin{abstract}
Changes in the Atlantic overturning circulation have a strong influence on European temperatures, North American sea level and other climate phenomena worldwide. A meaningful assessment of associated societal impacts needs to be based on the full range of its possible future evolution. This requires capturing both the uncertainty in future warming pathways and the inherently long-term response of the ocean circulation. While probabilistic projections of the global mean and regional temperatures exist, process-based probabilistic assessments of large-scale dynamical systems such as the Atlantic overturning are still missing. Here we present such an assessment and find that a reduction of more than $50 \%$ in Atlantic overturning strength by the end of the $21^{\text {st }}$ century is within the likely range of an unmitigated climate change scenario (RCP8.5). By combining linear response functions derived from comprehensive climate simulations with the full range of possible future warming pathways, we provide probability estimates of overturning changes by the year 2100 . Within the constraints of this model representation, a weakening of more than $25 \%$ is very unlikely under a climate protection scenario (RCP2.6), but likely for unmitigated climate change. The method is able to reproduce the modelled recovery caused by climatic equilibration under climate protection scenarios
\end{abstract}

All authors at

Potsdam Institute for Climate Impact Research, Potsdam, Germany

C.-F. Schleussner also at

Climate Analytics, Berlin, Germany

E-mail: schleussner@pik-potsdam.de

A. Levermann also at

Institute of Physics, Potsdam University, Potsdam, Germany

E-mail: levermann@pik-potsdam.de

M. Meinshausen also at

School of Earth Sciences, University of Melbourne, Victoria, Australia

E-mail: malte.meinshausen@unimelb.edu.au 
which provides confidence in the approach. Within this century, a reduction of the Atlantic overturning is a robust climatic phenomena that intensifies with global warming and needs to be accounted for in global adaptation strategies.

Keywords Atlantic meridional overturning circulation, probabilistic projections, linear response function

\section{Introduction}

The Atlantic Meridional Overturning Circulation (AMOC) is a key component of the global climate system. Observational estimates find a poleward heat transport of about $1.3 \pm 0.4 \mathrm{PW}$ at $26^{\circ} \mathrm{N}[8]$, which accounts for about $85 \%$ of global oceanic meridional heat transport at this latitude[3]. Future changes of the AMOC could affect the North Atlantic sea-level[29,11] and carbon sink[32] as well as the North Atlantic ocean ecosystem [18], the position of the Intertropical Convergence Zone, the El-Nino southern oscillation and the Indian summer monsoon [31]. Analysis of the CMIP5 model ensemble reveals a wide model spread both in their equilibrium AMOC strength and in the projected reduction [26]. A probabilistic approach allows to capture the different long-term responses, combine these into a quantitative assessment and to systematically assess the associated uncertainties.

Here we investigate the magnitude of the AMOC decline that is forced by the global increase of greenhouse gases and the associated global warming (see Fig. S1). The rate of temperature increase associated with three of the four Representative Concentration Pathways (RCPs) [25] is very rapid compared to natural temperature variations within the Holocene and projected to be most pronounced in the high northern latitudes[22]. The response to the resulting spatially diverse ocean heat-uptake[10] is found to dominate AMOC weakening across coupled climate models $[6,7,19]$, which provides the basis for the highly simplified approach followed here.

\section{Calibration procedure}

In this study, we apply a linear response theory approach to express the AMOC change $\Delta M(t)$ to a climate forcing $F\left(t^{\prime}\right)$ by a convolution with a model-dependent response function $R\left(t-t^{\prime}\right)$ :

$$
\Delta M(t)=\int_{0}^{t} d t^{\prime} F\left(t^{\prime}\right) R\left(t-t^{\prime}\right) .
$$

This linear response theory was applied successfully to emulate global temperatures and precipitation change in response to greenhouse gas concentration changes[5] and global sea-level rise including steric and ice-sheet contributions $[27,13]$. The linear response approach is a time-dependent perturbation analysis method. Therefore, the temporal change in AMOC strength is related 
to the temporal change in the perturbation, in this case the first derivative of the global mean surface air temperature (GMT) $d T_{g m t}(t) d t^{-1}$. The analysis further needs to account for potential time delays as well as a long-term response to the forcing, since multi-decadal adjustment time scales of the AMOC are physically expected.

The response function can take any functional form which can, in principle, be deduced from an infinitely long time series of an arbitrarily forced simulation or from the response to a step-function forcing. Due to limited and specific data available we assume a specific functional form following the one identified by [27] for oceanic heat uptake. Our choice is justified ex post by its ability to reproduce the AOGCM's AMOC response to different warming scenarios.

The form $R(t)=M_{0} \cdot t^{\alpha}$ yields the best results for $\alpha \approx-0.5$ which is the response function of the one-dimensional diffusion equation. We choose the value $\alpha=-0.5$ for simplicity, because the optimal value does not improve the fit significantly. It is important to note that this does not mean that the AMOC response is solely associated with vertical diffusion in the ocean, but rather that the influence of the change in global mean surface air temperature on the AMOC reduction can be described by

$$
\Delta M(t)=M_{0} \int_{0}^{t-\tau} \frac{d T_{g m t}\left(t^{\prime}\right)}{d t^{\prime}} \cdot \frac{d t^{\prime}}{\sqrt{t-t^{\prime}-\tau}},
$$

where the scaling coefficient $M_{0}$ and the time-delay $\tau$ are independent calibration coefficients. Although AMOC equilibrium strength as well as reduction differ widely across the models, models with a stronger equilibrium AMOC tend to show a stronger reduction (see Figure S4, $[6,12]$ ). Consequently, we assess the relative AMOC reduction with respect to the pre-industrial value ( $\Delta M$ is given in percentage change). The time under the square root has been non-dimensionalized by division of one year and $M_{0}$ has the unit $K^{-1}$. It is important to highlight that such a linear response approach assumes a strong forcing to dominate the systems response as we find it to be the case for the GMT increase in the given RCP scenarios. Under less rigorous conditions, the relation between AMOC and GMT becomes considerably more complex [30,17]. Additionally, no robust relation between AMOC weakening and GMT increase by 2100 over the model ensemble has been found (see Figure S5), which implies that differences in the AMOC response do not contribute significantly to the ensemble spread in transient climate sensitivity. Eq. 2 is calibrated to eight individual models of the Coupled Model Intercomparison project (CMIP5) [23] ensemble by minimizing the least-square differences for one realization of the RCP2.6, 4.5 and 8.5 scenarios over the $21^{\text {st }}$ century equally weighted.

Since our method does not account for short term natural variability, all timeseries were low-pass filtered using a Hamming filter with a cut-off frequency of 20 years. The RCP scenarios are concatenated with the historical scenario for each model. The results are depicted in Fig. 1 and the corresponding parameter fits are provided in Tab. S1. The resulting time-delays 
that range from 23 to 34 years for all models except MRI-CGCM3 is consistent with basin-wide AMOC adjustment on an interdecadal time-scale[9].

Our approach captures both the continuous AMOC weakening under the RCP8.5 scenario and its recovery under RCP2.6 and RCP4.5 that is present in most models, although some deviations between the model output and the fitting results are apparent. The AMOC recovery present for the RCP2.6 and RCP4.5 in several models is even more pronounced in the simulations until 2300 which was computed by four models (Fig. S2) and we find good agreement between our projections and the model output even far outside the calibration range for the CanESM2, CESM1-CAM5 and MPI-ESM-LR model.

The strongest deviations between the model and the emulation using Eq. 2 is found for the CNRM-CM5 model. For this model, the AMOC shows no clear scenario dependency for the RCP2.6 and RCP4.5 until 2100, which is not captured by our emulator approach, and the weakening for the RCP 8.5 scenario is overestimated and underestimated for the RCP4.5 until 2300. Taken together, these deviations indicate that other mechanisms, likely changes in the freshwater budget that do not follow our simplified linear response function approach, are dominating on longer time scales in this model. For further analysis, we restrict our interpolation method to the period up to the year 2100 .

\section{Projections}

Eq. 2 was successfully calibrated to complex model output comprising a variety of different AMOC responses and can be used to interpolate in the vicinity of the existing model simulations to assess a probability distribution for the future weakening of the AMOC under different emission pathways. To this end we use scenario dependent $\mathrm{N}=600$ ensembles of GMT trajectories obtained from historically constrained MAGICC6-simulations[14] (see Supplementary Material for further detail). AMOC trajectories are derived for each model parameter set based on the 600 GMT realizations by MAGICC6. Herein the time-delay is fixed for a given climate model and the scaling coefficient $M_{0}$ is randomly chosen from a normal distribution with mean and standard deviation determined by the calibration procedure. Results for the individual ensemble members are given in Table S4.

Median projections, the 50, 66 and $90 \%$ percentiles as well as the underlying model ensemble trajectories are shown in Fig. 2 for different RCPs and detailed in Tab. 1. For the RCP2.6, we find the strongest AMOC weakening in the second half of the $21^{\text {st }}$ century and a successive recovery to about $9 \%$ relative to the preindustrial period (1850-1900). The likely range that comprises $66 \%$ of all trajectories ranges from $5 \%$ to $15 \%$ weakening. As a consequence of the explicitly time-dependent response function and despite the time-delayed response, the AMOC stabilizes for monotonously rising temperatures under the RCP 4.5 scenario at about $19 \%(12 \%-30 \%)$ below the pre-industrial value. By contrast, a continuous AMOC weakening is found for RCP6.0 and RCP8.5 
with a median reduction of about $24 \%(16 \%-35 \%)$ and $38 \%(25 \%-56 \%)$, respectively. The uncertainty increases with increasing temperature. Note that our calibration range set by the underlying model ensemble does not comprise the full temperature projections of the MAGICC6 model under the RCP8.5, but is limited to a maximum of about $3.5^{\circ} \mathrm{C}$ warming by 2070 relative to 1980 1999 levels. Thus, temperature trajectories above the upper limit of the likely range are extrapolating outside the calibration range and cannot be assessed.

\section{Discussion and Conclusions}

The median projections of AMOC weakening in 2100 presented here match well with the ensemble average of the underlying CMIP5 model ensemble (RCP2.6: 9\%, RCP4.5: 20\%,RCP8.5: 35\%, see Figure 2 and Table S2). This is not a trivial finding since the AMOC trajectories differ widely over the model ensemble (see Figure 2). These AMOC trajectories are a composition of the model specific AMOC response to GMT change as well as the GMT change in response to the emission pathways that differ between the models as a result of the model-dependent transient climate sensitivity (see Figure S3 and Table S3). By resolving the AMOC response to the MAGICC6 GMT projections for each model parameter set we can assess the relevance of the model's GMT trajectory for the projected AMOC change (see Table S4). The CMIP5 ensemble spread is particularly large for the RCP2.6 (mean weakening: $9 \%$, standard deviation (std): $9 \%$ ) and is considerably lowered, if the model dependent GMT response is replaced by the MAGICC6 projections (std: $3 \%$ ). Accounting for the model dependent GMT response allows to narrow the uncertainty range in AMOC projections over the 21st century in particular for climate protection scenarios. The projections provided in this study are consistent with projections of the IPCC AR5 [2] report and historically constrained Bayesian model studies[24]. In an emulator approach based on CMIP3 models, an AMOC reduction of about $11 \%(22 \%)$ for the RCP2.6 (RCP4.5) was found[16], which indicate some robustness of the results across methods but also model ensembles.

From our analysis, we would expect a delayed response of the AMOC to changes in GMT by about 23-34 years. Rapid increase in GMT has been observed since the 1980s and continuous AMOC observations suggest that the AMOC has weakened over the second half of the last decade [21], which would correspond to a time-delay well within the identified range. However, since continuous AMOC observations are only available since 2004, clear attribution of this trend to external climate forcing rather than internal variability is not possible [15].

Limitations of the approach relate to the representation of the AMOC in the model ensemble, its forcing in comprehensive climate models and a potential instability of the AMOC. While explicitly time-dependent, the linear response approach will yield a linear response of the AMOC with respect to the temperature forcing. If a weak temperature forcing initiates a collapse of the 
AMOC which is independent of the successive forcing the response will not be captured properly by the approach. This limitations is particularly relevant for low temperature scenarios. Furthermore, none of the models includes meltwater from the Greenland ice sheet. Meltwater influx from Greenland equivalent to about $10 \mathrm{~cm}$ global sea-level [4] has been found to lead to an additional AMOC reduction by about $5 \%$ [16] and could prevent the recovery seen for $\mathrm{RCP} 2.6$ and RCP4.5. As a consequence, a cessation of the AMOC within the $21^{\text {st }}$ century cannot be ruled out under unmitigated climate change and needs to be accounted for in future adaptation strategies.

While the median AMOC reduction in Fig. 2 shows a clear scenario dependence, the uncertainty that arises from the future climate response is substantial. Compared to the mere model spread, the probabilistic approach allows for more elaborated statements on future AMOC reduction as might be useful in climate impact analysis such as projections of dynamic sea-level rise at the North American Atlantic coastline that has been found to be strongly affected by AMOC weakening $[28,1,20]$.

Acknowledgements We acknowledge the World Climate Research Programmes Working Group on Coupled Modelling, which is responsible for CMIP, and we thank the climate modelling groups for producing and making available their model output. For CMIP the US Department of Energys Program for Climate Model Diagnosis and Intercomparison provides coordinating support and led development of software infrastructure in partnership with the Global Organization for Earth System Science Portals. The research leading to these results has received funding from the European Union Seventh Framework Programme FP7/20072013 under grant agreement No. 603864. The authors would like to thank the reviewers for their comments that helped to improve the manuscript. 
Fig. 1 Projection of the AMOC weakening using the linear-response function (dashed) compared to the AMOC as simulated by the corresponding comprehensive CMIP5 climate models (solid line, $\mathrm{MO}=$ Model Output, low-pass filtered with a 20 year Hamming filter window). AMOC reduction is given relative to the pre-industrial period (1850-1900).

Fig. 2 Probabilistic Projections of the AMOC (relative to the preindustrial period (18501900)) based on MAGICC6 GMT projections (see Figure S3). The ensemble median as well as the 50,66, and $90 \%$ quantiles are highlighted. For comparison, the ensemble mean for the CMIP5 model ensemble is depicted in grey and individual models are overlayed as dotted lines (low-pass filtered with a 20 year Hamming filter window). Models that deviate most strongly from the ensemble mean are labelled accordingly. 
Table 1 Probabilistic assessment of the AMOC reduction for the different RCP scenarios in percentage reduction relative to the preindustrial AMOC strength (1850-1900). The likely range corresponds to the $66 \%$-percentile; the very likely range corresponds to the $90 \%$ percentile around the median of the distribution. Note that the upper limit of the RCP 8.5 scenario lies outside the calibration range and can not be assessed.

\begin{tabular}{lccc}
\hline \hline & Median & Likely Range & Very Likely Range \\
RCP2.6 & 9 & $5-15$ & $3-20$ \\
RCP4.5 & 19 & $12-30$ & $8-39$ \\
RCP6.0 & 24 & $16-35$ & $11-46$ \\
RCP 8.5 & 38 & $25-56$ & $18-*$ \\
\hline
\end{tabular}




\section{References}

1. Bouttes, N., Gregory, J.M., Kuhlbrodt, T., Smith, R.S.: The drivers of projected North Atlantic sea level change. Climate Dynamics 43(5-6), 1531-1544 (2013). DOI 10.1007/s00382-013-1973-8

2. Collins, M., Knutti, R., Arblaster, J.M., Dufresne, J.L., Fichefet, T., Friedlingstein, P., Gao, X., Gutowski, W.J., Johns, T., Krinner, G., Shongwe, M., Tebaldi, C., Weaver, A.J., Wehner, M.: Climate Change 2013: The Physical Science Basis. Contribution of Working Group I to the Fifth Assessment Report of the Intergovernmental Panel on Climate Change, chap. Long-term Climate Change: Projections, Commitments and Irreversibility. Cambridge University Press, Cambridge, United Kingdom and New York, NY, USA (in press)

3. Fasullo, J.T., Trenberth, K.E.: The Annual Cycle of the Energy Budget. Part II: Meridional Structures and Poleward Transports. Journal of Climate 21(10), 2313-2325 (2008). DOI 10.1175/2007JCLI1936.1

4. Fettweis, X., Franco, B., Tedesco, M., van Angelen, J.H., Lenaerts, J.T.M., van den Broeke, M.R., Gallée, H.: Estimating the Greenland ice sheet surface mass balance contribution to future sea level rise using the regional atmospheric climate model MAR. The Cryosphere 7(2), 469-489 (2013). DOI 10.5194/tc-7-469-2013

5. Good, P., Gregory, J.M., Lowe, J.A.: A step-response simple climate model to reconstruct and interpret AOGCM projections. Geophysical Research Letters 38(1), L01,703 (2011). DOI 10.1029/2010GL045208

6. Gregory, J., Dixon, K., Stouffer, R., Weaver, A., Driesschaert, E., Eby, M., Fichefet, T., Hasumi, H., Hu, A., Jungclaus, J., et al.: A model intercomparison of changes in the Atlantic thermohaline circulation in response to increasing atmospheric $\mathrm{CO}$ concentration. Geophysical Research Letters 32, L12703 (2005). DOI 10.1029/2005GL023209

7. Gregory, J.M., Tailleux, R.: Kinetic energy analysis of the response of the Atlantic meridional overturning circulation to CO2-forced climate change. Climate Dynamics 37(5-6), 893-914 (2011). DOI 10.1007/s00382-010-0847-6

8. Johns, W.E., Baringer, M.O., Beal, L.M., Cunningham, S.A., Kanzow, T., Bryden, H.L., Hirschi, J.J.M., Marotzke, J., Meinen, C.S., Shaw, B., Curry, R.: Continuous, Array-Based Estimates of Atlantic Ocean Heat Transport at 26.5 degrees N. Journal of Climate 24(10), 2429-2449 (2011). DOI 10.1175/2010JCLI3997.1

9. Johnson, H., Marshall, D.: A theory for the surface Atlantic response to thermohaline variability. Journal of Physical Oceanography 32, 1121-1132 (2002)

10. Kuhlbrodt, T., Gregory, J.M.: Ocean heat uptake and its consequences for the magnitude of sea level rise and climate change. Geophysical Research Letters 39, L18,608 (2012). DOI 10.1029/2012GL052952. URL http://doi.wiley.com/10.1029/2012GL052952

11. Levermann, A., Griesel, A., Hofmann, M., Montoya, M., Rahmstorf, S.: Dynamic sea level changes following changes in the thermohaline circulation. Climate Dynamics 24 347-354 (2005)

12. Levermann, A., Mignot, J., Nawrath, S., Rahmstorf, S.: The Role of Northern Sea Ice Cover for the Weakening of the Thermohaline Circulation under Global Warming. Journal of Climate 20(16), 4160-4171 (2007). DOI 10.1175/JCLI4232.1

13. Levermann, A., Winkelmann, R., Nowicki, S., Fastook, J.L., Frieler, K., Greve, R., Hellmer, H.H., Martin, M.A., Meinshausen, M., Mengel, M., Payne, A.J., Pollard, D., Sato, T., Timmermann, R., Wang, W.L., Bindschadler, R.A.: Projecting antarctic ice discharge using response functions from searise ice-sheet models. Earth System Dynamics 5, 271-293 (2014). DOI 10.5194/esd-5-271-2014.

14. Meinshausen, M., Meinshausen, N., Hare, W., Raper, S.C.B., Frieler, K., Knutti, R., Frame, D.J., Allen, M.R.: Greenhouse-gas emission targets for limiting global warming to $2{ }^{\circ} \mathrm{C}$. Nature 458(7242), 1158-1162 (2009)

15. Roberts, C.D., Jackson, L., McNeall, D.: Is the 20042012 reduction of the atlantic meridional overturning circulation significant? Geophysical Research Letters 41(9), 3204-3210 (2014). DOI 10.1002/2014GL059473

16. Schleussner, C.F., Frieler, K., Meinshausen, M., Yin, J., Levermann, A.: Emulating atlantic overturning strength for low emission scenarios: consequences for sea-level rise 
along the north american east coast. Earth System Dynamics 2(2), 191-200 (2011). DOI 10.5194/esd-2-191-2011

17. Schleussner, C.F., Runge, J., Lehmann, J., Levermann, A.: The role of the North Atlantic overturning and deep-ocean for multi-decadal global-mean-temperature variability. Earth System Dynamics 4, 967-1013 (2014). DOI doi:10.5194/esdd-4-967-2013.

18. Schmittner, A.: Decline of the marine ecosystem caused by a reduction in the Atlantic overturning circulation. Nature 434(7033), 628-633 (2005). DOI 10.1038/nature03476

19. Sijp, W.P., Gregory, J.M., Tailleux, R., Spence, P.: The Key Role of the Western Boundary in Linking the AMOC Strength to the NorthSouth Pressure Gradient. Journal of Physical Oceanography 42(4), 628-643 (2012). DOI 10.1175/JPO-D-11-0113.1

20. Slangen, A.B.A., Carson, M., Katsman, C.A., van de Wal, R.S.W., Köhl, A., Vermeersen, L.L.A., Stammer, D.: Projecting twenty-first century regional sea-level changes. Climatic Change 124(1-2), 317-332 (2014). DOI 10.1007/s10584-014-10809. URL http://link.springer.com/10.1007/s10584-014-1080-9

21. Smeed, D.a., McCarthy, G., Cunningham, S.a., Frajka-Williams, E., Rayner, D., Johns, W.E., Meinen, C.S., Baringer, M.O., Moat, B.I., Duchez, a., Bryden, H.L.: Observed decline of the Atlantic Meridional Overturning Circulation 2004 to 2012. Ocean Science Discussions 10(5), 1619-1645 (2013). DOI 10.5194/osd-10-1619-2013

22. Stocker, T.F., Qin, D., Plattner, G.K., Alexander, L.V., Allen, S.K., Bindoff, N.L., Breon, F.M., Church, J.A., Cubasch, U., Emori, S., Forster, P., Friedlingstein, P., Gillett, N., Gregory, J.M., Hartmann, D.L., Jansen, E., Kirtman, B., Knutti, R., Kumar, K.K., Lemke, P., Marotzke, J., Masson-Delmotte, V., Meehl, G.A., Mokhov, I., Piao, S., Ramaswamy, V., Randall, D., Rhein, M., Rojas, M., Sabine, C., Shindell, D., Talley, L.D., Vaughan, D.G., Xie, S.P.: Climate Change 2013: The Physical Science Basis. Contribution of Working Group I to the Fifth Assessment Report of the Intergovernmental Panel on Climate Change, chap. Technical Summary. Cambridge University Press, Cambridge, United Kingdom and New York, NY, USA (in press)

23. Taylor, K.E., Stouffer, R.J., Meehl, G.A.: An overview of cmip5 and the experiment design. Bulletin of the American Meteorological Society 93(4), 485-498 (2012). DOI 10.1175/BAMS-D-11-00094.1

24. Urban, N.M., Keller, K.: Probabilistic hindcasts and projections of the coupled climate, carbon cycle and Atlantic meridional overturning circulation system: a Bayesian fusion of century-scale observations with a simple model. Tellus A (2010). DOI 10.1111/j.16000870.2010.00471.x

25. Van Vuuren, D.P., Edmonds, J., Kainuma, M., Riahi, K., Thomson, A., Hibbard, K., Hurtt, G.C., Kram, T., Krey, V., Lamarque, J.F., et al.: The representative concentration pathways: an overview. Climatic Change 109(1-2), 5-31 (2011)

26. Weaver, A.J., Sedláček, J., Eby, M., Alexander, K., Crespin, E., Fichefet, T., PhilipponBerthier, G., Joos, F., Kawamiya, M., Matsumoto, K., Steinacher, M., Tachiiri, K. Tokos, K., Yoshimori, M., Zickfeld, K.: Stability of the Atlantic meridional overturning circulation: A model intercomparison. Geophysical Research Letters 39(20), 1-7 (2012). DOI 10.1029/2012GL053763

27. Winkelmann, R., Levermann, A.: Linear response functions to project contributions to future sea level. Climate Dynamics 40(11-12), 2579-2588 (2013). DOI 10.1007/s00382012-1471-4. URL http://dx.doi.org/10.1007/s00382-012-1471-4

28. Yin, J., Goddard, P.B.: Oceanic control of sea level rise patterns along the East Coast of the United States. Geophysical Research Letters 40(20), 5514-5520 (2013). DOI 10.1002/2013GL057992

29. Yin, J., Schlesinger, M.E., Stouffer, R.J.: Model projections of rapid sea-level rise on the northeast coast of the United States. Nature Geoscience 2, 262-266 (2009)

30. Zanchettin, D., Rubino, A., Jungclaus, J.H.: Intermittent multidecadal-to-centennial fluctuations dominate global temperature evolution over the last millennium. Geophysical Research Letters 37(14), L14,702 (2010). DOI 10.1029/2010GL043717

31. Zhang, R., Delworth, T.: Simulated Tropical Response to a Substantial Weakening of the Atlantic Thermohaline Circulation. Journal of Climate 18(2002), 1853-1860 (2005)

32. Zickfeld, K., Eby, M., Weaver, A.J.: Carbon-cycle feedbacks of changes in the atlantic meridional overturning circulation under future atmospheric co2. Global Biogeochemical Cycles 22(3) (2008) 


\section{University Library}

\section{- M M N E R VA A gateway to Melbourne's research publications}

Minerva Access is the Institutional Repository of The University of Melbourne

Author/s:

Schleussner, C-F;Levermann, A;Meinshausen, M

Title:

Probabilistic projections of the Atlantic overturning

Date:

2014-12-01

Citation:

Schleussner, C. -F., Levermann, A. \& Meinshausen, M. (2014). Probabilistic projections of the Atlantic overturning. CLIMATIC CHANGE, 127 (3-4), pp.579-586. https://doi.org/10.1007/ s10584-014-1265-2.

Persistent Link:

http://hdl.handle.net/11343/282781 